\title{
ANTROPOLOGÍA DE LA SALUD: UNA MIRADA ACTUAL
}

\author{
HEALTH ANTHROPOLOGY: A CURRENT PERSPECTIVE
}

\author{
Oswaldo Salaverry ${ }^{1, a}$
}

\begin{abstract}
La Antropología Médica es una disciplina cuyo objeto ha estado cercano a la práctica médica desde la antigüedad, y que con la actual globalización y la mayor visibilidad de la cultura adquiere una renovada importancia, especialmente para la salud pública, pese a lo cual es prácticamente desconocida para amplios sectores de la medicina contemporánea. Sus antecedentes podemos remontarlos a las observaciones sobre el comportamiento de los diversos pueblos y cómo se relacionaban con la salud de esas poblaciones en los tratados hipocráticos, y los podemos seguir cómo notas importantes en autores tan diversos como Paracelso y su reclamo a la medicina de su época para adquirir la experiencia necesaria observando las distintas formas de enfermedad y como eran tratadas por los más diversos pueblos. A lo largo de los últimos 2000 años, y hasta un periodo muy reciente la mirada médica hacia la sociedad ha tenido por exclusivo objeto conocer mejor las circunstancias que rodean la percepción de la enfermedad y como es enfrentada, por una sociedad determinada.
\end{abstract}

La moderna Antropología Médica comienza alrededor de los años 60 del siglo XX, a partir del desarrollo de la antropología cultural norteamericana, en sus primeras etapas, como señala Menendez ${ }^{(1)}$ tuvo una especial dedicación a las medicinas tradicionales. Su desarrollo posterior, sin embargo, ha estado signado por al menos dos tendencias, la primera afincada en la práctica clínica y la segunda en una perspectiva desde la antropología general. La primera de estas tendencias es la que tiene mayores antecedentes desde campos como la medicina folclórica y el estudio de los sistemas médicos populares, y es en esta forma como surge la disciplina en los países latinoamericanos, incluyendo el Perú; mientras que la segunda ha tenido un mayor desarrollo especialmente en países anglosajones, llegando, incluso, a objetar que la antropología médica se vincule con la medicina y hasta a proponer cambiar el nombre hacia Antropología de la Salud para alejarse de una supuesta innecesaria medicalización de la disciplina.

En el presente número de la revista, dedicado en su simposio a esta amplia disciplina, participan tanto médicos y personal de salud como antropólogos, reunidos alrededor de una visión conjunta de aplicación de la antropología en la salud pública o de un mayor conocimiento de los procesos que deben ser tomados en cuenta para una práctica médica. Esta orientación es coherente con la perspectiva general de la revista que tiene entre sus objetivos el tratar temas que se vinculen directamente con la salud pública y no solo debates teóricos. Claro está que esta elección no desestima en absoluto una visión más teórica de la antropología médica, pero es coherente con el desarrollo latinoamericano de la disciplina; somos un subcontinente en el que la diversidad cultural y por tanto su vínculo con la salud no es un tópico que debe buscarse en lugares alejados, sino que está presente en las urbes y permea toda la sociedad. Este acercamiento a la antropología médica es coherente con los antecedentes y cultivadores clásicos de esta disciplina en el Perú, que incluye a eminentes médicos como Hermilio Valdizán quien junto con Ángel Maldonado reunió un repertorio valioso de prácticas tradicionales en su célebre "La medicina popular peruana", pero también incluye a otros médicos, psiquiatras en su mayoría, que practicaron lo que entendían era el estudio de la medicina folklórica, encontramos allí los estudios de Federico Sal y Rosas y sus estudios sobre el síndrome cultural del "susto" y la terapia tradicional para su tratamiento; están también los trabajos de Monge y los de Carlos Alberto Seguín así como los de Gutiérrez Noriega sobre el cocainismo.

Entre los trabajos dedicados al tema de la antropología médica en el presente número de la RPMESP destacan, Bernales et al. con "Desafíos en la atención sanitaria de migrantes internacionales en Chile" (2), artículo en el que abre un debate sobre la migración internacional y los retos que implica para el trabajador de salud, uno de los cuales es enfrentarse al componente cultural de la población foránea, para lo cual no cuenta con las herramientas necesarias en su formación profesional. Este tema se enmarca en una perspectiva mucho más amplia que incluye las migraciones internas, lo que es una constante que ha cambiado la composición social de nuestras ciudades y constituye uno de los temas que la antropología médica tiene como pendiente. Los

\footnotetext{
Universidad Nacional Mayor de San Marcos. Lima, Perú.

a Médico cirujano, doctor en Medicina

Recibido: 16/06/2017 Aprobado: 21/06/2017 En línea: 28/06/2017
}

Citar como: Salaverry O. Antropología de la salud: una mirada actual. Rev Peru Med Exp Salud Publica. 2017;34(2): 165-6. doi: 10.17843/rpmesp.2017.342.2988 
estudios sobre poblaciones indígenas y mestizas y su riesgo en salud desde una perspectiva antropológica y social son abordados por Yeckting en "Situacion de riesgo y salud de los adolescentes en el valle de los ríos Apurimac, Ene y Mantaro en Perú" (3). La zona abordada corresponde a una región en la cual la migración andina de raíces quechuas básicamente, como consecuencia de fenómenos económicos complejos, se ha encontrado con una población indígena amazónica, los ashaninka. Nos muestra así la complejidad de la interculturalidad que no se refiere solo a la de la cultura hegemónica enfrentada a una población nativa sino a culturas marginadas obligadas a integrarse entre sí, frente a un estado ajeno a ambas culturas. Otro de los múltiples temas en los que una perspectiva antropológica es imprescindible.

Murillo con "Entre la aclimatación a la altura, la antropología médica y la utopía civilizatoria. Cartografía de la evolución del pensamiento de Carlos Monge Medrano sobre el proceso de salud-enfermedad de poblaciones andinas" (4), describe prolijamente, a través de un científico, inicialmente solo orientado hacia la biomedicina, la evolución de un pensamiento no solo individual sino social sobre el indígena. Nos muestra cómo del debate médico y fisiológico se genera una nueva perspectiva, también científica, que intenta superar el debate entre indigenistas e hispanistas en la primera mitad del siglo XX. Pinilla, por su parte, con "Hospital San Juan de Dios: actor y víctima de las políticas públicas en Colombia" (5) asume las herramientas metodológicas de la antropología para mostrar un conflicto contemporáneo del sector salud, consecuencia de políticas públicas que rompen un modelo institucionalizado a través de un largo proceso social.

La complejidad de la creación de sentidos sociales y su relación con un entorno histórico-social, es el tema que aborda Castillo et al. en "Salud intercultural. El ciclo vital en los Andes" (6), su análisis a partir de fuentes documentales y etnográficas nos brinda una mirada a algunos comportamientos sociales que suelen ser interpretados etnocéntricamente por la medicina moderna. Las edades y los grupos etarios dependen también de la cultura y no solo de factores biológicos que suponemos inconmovibles. Finalmente, Santa Maria en "Taki Onqoy: Epidemia de intoxicación por exposición al mercurio en Huamanga del siglo XVI" (7) nos recuerda, desde una perspectiva histórica, el conflicto de culturas que signó la relación con los conquistadores, quienes impusieron un cambio en la estructura económica, pasando de una economía agraria a una extractiva y provocando así no solo cambios sociales y culturales sino sanitarios que impactaron profundamente en el imaginario social de la población originaria, recreando en ella nuevas formas explicativas de una realidad inicialmente incomprensible. Con formas y actores diferentes, el drama de los entornos intervenidos por la modernidad en su búsqueda de nuevas riquezas continúa siendo la fuente más importante de conflictos sociales y sigue con una fuerte impronta de conflicto cultural entre dos modelos de desarrollo que pueden parecer incompatibles

El conjunto de artículos mencionados solo puede reflejar, como ya se anticipó, una pequeña muestra de la diversidad de perspectivas que abre la antropología médica, pero también nos confronta con la necesidad de incentivar que esta disciplina se incorpore a la academia, un estudio realizado con el auspicio del Organismo Andino de Salud muestra la desoladora realidad: solo un puñado de las escuelas formadoras de personal de salud de la región andina incluye temas, no digamos asignaturas, formativas en antropología médica. En muy pocas Escuelas de Medicina se incluye una asignatura de Antropología General y usualmente solo se pueden encontrar algunas asignaturas electivas de Antropología Médica en algún programa de maestría y doctorado en antropología general. Un reciente Simposio de antropología medica en el Perú, paradójicamente, convocó a muchos académicos, lo que refleja un bullente interés por el tema, pero que parte de la Antropología general y cultural. Desde las ciencias de la salud, hegemónicamente dominadas por un sistema de salud biomédico, recuperativo y centrado en hospitales, hay aún mucho por recorrer.

\section{REFERENCIAS BIBLIOGRÁFICAS}

1. Menendez E. Aproximación crítica al desarrollo de la antropología médica en América Latina. Nueva Antropología. 1985;(28):11-28.

2. Bernales M, Cabieses B, McIntyre AM, Chepo M. Desafíos en la atención sanitaria de migrantes internacionales en Chile. Rev Peru Med Exp Salud Publica. 2017;34(2):167-75. doi: 10.17843/rpmesp.2017.342.2510.

3. Yeckting Vilela F. Situación de riesgo y salud de los adolescentes en el valle del río Apurímac, Ene y Mantaro en Perú. Rev Peru Med Exp Salud Publica.
2017;34(2):273-9. doi: 10.17843/ rpmesp.2017.342.2867.

4. Murillo JP. Entre la aclimatación a la altura, la antropología médica y la utopía civilizatoria. Cartografía de la evolución del pensamiento de Carlos Monge Medrano sobre el proceso saludenfermedad de poblaciones andinas. Rev Peru Med Exp Salud Publica. 2017;34(2):280-6. doi: 10.17843/ rpmesp.2017.342.2880.

5. Pinilla MY, Abadía CE. Hospital San Juan de Dios: actor y víctima de las políticas públicas en Colombia.
Rev Peru Med Exp Salud Publica. 2017;34(2):287-92. doi: 10.17843/ rpmesp.2017.342.2888.

6. Santa Maria LA. Salud intercultural: el ciclo vital en los andes. Rev Peru Med Exp Salud Publica. 2017;34(2):293-8. doi: 10.17843/rpmesp.2017.342.2732.

7. Santa Maria LA. Taki Onqoy: epidemia de intoxicación por exposición al mercurio en Huamanga del siglo XVI. Rev Peru Med Exp Salud Publica. 2017;34(2):337-42. doi: 10.17843/ rpmesp.2017.342.2738. 